\title{
Development of Technologies for Cooling Strips of Steel 60C2XA on a Retractable Roller Conveyor
}

\author{
${ }^{1}$ Rustem Kozbagarov, ${ }^{2}$ Timur Chigambaev, ${ }^{2}$ Talgat Agimov, ${ }^{1}$ Zhastalap Abilkaiyr \\ ${ }^{2}$ Batyrkhan Kyrykbaev and ${ }^{2}$ Algazy Zhauyt \\ ${ }^{1}$ Satbayev University, 050013 Almaty, Kazakhstan \\ ${ }^{2}$ Almaty University of Power Engineering and Telecommunication, 050013 Almaty, Kazakhstan \\ ali84jauit@mail.ru
}

\begin{abstract}
These days, ensuring the high quality of thin products $(0.6-2.0 \mathrm{~mm})$ is the most promising direction for the development of hot-rolled strip production. Hot-rolled strips can be used in place of a more expensive cold-rolled strip. In the production of ultra-thin cold-rolled strips, the use of thin hot-rolled strips as a rolling stock allows to significantly reduce the cost of the latter (at least 20\%). However, the replacement of cold-rolled strips with hot-rolled ones is possible only in the case when hot-rolled steel will completely satisfy a number of technological requirements, i.e. have a satisfactory microstructure and the required level of mechanical properties, etc. An effective tool for influencing the formation of the structure and properties of steel is targeted hot rolling sheets on a suitable mill in combination with controlled cooling. Therefore, the use of reserves to improve the quality of sheets by improving the design of the mill and the temperature-deformation modes of rolling becomes one of the most important tasks facing producers of rolled metal. It is known that hot deformation of austenite with controlled temperature-deformation mode and subsequent cooling of rolled products is one of the most effective ways to improve the properties of rolled products.
\end{abstract}

Key words: Cold-rolled, hot-rolled, temperature-deformation, austenitization, longitudinal-wedge mill, effective ways

\section{INTRODUCTION}

Numerous schemes of Thermo Mechanical processing (TMO) rolled products have been developed and are being actively used. In the production of carbon sheets it is great interest to provide a scheme for the formation of perlite, based on the plastic deformation of steel in the austenite state and the subsequent isothermal transformation of austenite in the pearlite region (Deshpande and Murthy, 1997). Other things being equal, an increase in the cooling rate leads to an increase in the strength properties of the rolled metal. This reduces the plastic properties. At a very high cooling rate a padded layer of metal forms on the surface of the strip (Zhong-feng et al., 2011). To the discrepancy between the mechanical properties of hot-rolled steel and the requirements of standards, i.e., to get a marriage can lead to heterogeneity of the microstructure along the thickness of the strip, increased hardness and "Brittleness" of the incandescent surface (Karandaev et al., 2017). Thus, the microstructure of hot-rolled thin strips produced on known mills is often characterized by considerable grain size (large grain on the surface) which leads to the formation of various defects when using such metal for cold stamping. The main reason for the heterogeneity of thin strips is the incorrect assignment of temperature-deformation modes of rolling and cooling (Maklakova et al., 2015). Since, hot-rolling mills essentially, differ in design (in terms of the number and location of stands, coilers the length of intermediate and with drawing roller tables, the power of the main drives, etc.) the technology of production of sheet products on them differs. Technological solutions are effective for one mill is often unacceptable for another (Shilyaev et al., 2013). Therefore, the study of the influence of temperature regimes rolling and quenching as well as the cooling of strips on the quality of hot-rolled steel, rolled and chilled in a new mill and a retractable roller table is great importance. The plastic deformation of samples from steel A1 was carried out on the "Tension-compression" module. The samples were heated at a rate of $100^{\circ} \mathrm{C} / \mathrm{sec}$ to a temperature of $1100^{\circ} \mathrm{C}$ and held at these temperatures $1 \mathrm{~h}$. Further, each heated sample was cooled to temperatures of $800-1000^{\circ} \mathrm{C}$, deformed by cyclic compression at the rolling speeds of the longitudinal-wedge mill (Table 1). When drawing up the

Corresponding Author: Algazy Zhauyt, Almety Univertsity of Power Engineering and Telecommunication (AUPET), 050013 Almaty, Kazakhstan, ali84jauit@mail.ru 
Table 1: The experimental design of phy sical modeling

\begin{tabular}{|c|c|c|c|c|c|c|c|c|c|c|}
\hline$\varepsilon_{1}(\%)$ & $t_{1}(\mathrm{sec})$ & $\varepsilon_{2}(\%)$ & $\mathrm{t}_{2}(\mathrm{sec})$ & $\varepsilon_{3}(\%)$ & $\mathrm{t}_{3}(\mathrm{sec})$ & $\varepsilon_{4}(\%)$ & $\mathrm{t}_{4}(\mathrm{sec})$ & $\varepsilon_{5}(\%)$ & $\tau_{B}(\mathrm{sec})$ & $\tau_{\mathrm{BO}}(\mathrm{sec})$ \\
\hline \multicolumn{11}{|c|}{ Test temperature $800^{\circ} \mathrm{C}$} \\
\hline 25 & 4 & 22 & 3.0 & 18 & 2.2 & 18 & 1.6 & 12 & 2 & 10 \\
\hline 25 & 4 & 28 & 2.6 & 17 & 2.1 & 15 & 1.8 & 15 & 8 & 4 \\
\hline 35 & 3 & 22 & 3.0 & 18 & 2.2 & 11 & 1.9 & 9 & 6 & \\
\hline \multicolumn{11}{|c|}{ Test temperature $900^{\circ} \mathrm{C}$} \\
\hline 25 & 4 & 22 & 3.0 & 18 & 2.2 & 18 & 1.6 & 12 & 2 & 10 \\
\hline 25 & 4 & 28 & 2.6 & 20 & 2.1 & 15 & 1.8 & 15 & 8 & 4 \\
\hline 35 & 3 & 22 & 3.0 & 18 & 2.2 & 11 & 1.9 & 9 & 6 & 6 \\
\hline \multicolumn{11}{|c|}{ Test temperature $1000^{\circ} \mathrm{C}$} \\
\hline 25 & 4 & 22 & 3.0 & 18 & 2.2 & 18 & 1.6 & 12 & 2 & 10 \\
\hline 25 & 4 & 28 & 2.6 & 20 & 2.1 & 15 & 1.8 & 15 & 8 & 4 \\
\hline 35 & 3 & 22 & 3.0 & 18 & 2.2 & 11 & 1.9 & 9 & 6 & 6 \\
\hline
\end{tabular}

$\varepsilon_{1}$-Single reduction in the first stand; $t_{1}$-Interdisciplinary pause after the first stand; $\varepsilon_{2}$-Single reduction in the second stand; $t_{2}$-Interdisciplinary pause after the second stand; $\varepsilon_{3}$-Single reduction in the third stand; $\mathrm{t}_{3}$-Interdisciplinary pause after the third stand; $\varepsilon_{4}$-Single reduction in the fourth stand; $\mathrm{t}_{4}$-Interdisciplinary after the fourth stand; $\varepsilon_{5}$-Single reduction in the fifth stand; $\tau_{\mathrm{B}}$ Time cooling in air and $\tau_{\mathrm{B} 0}$-Time for cooling with water-air mixture

experiment plan, the time of the interdisciplinary pause was determined on the basis of the law by the constancy of seconds in rolling during a $5 \mathrm{~km}$ longitudinal-wedge mill (Randak, 1985). In the intervals of cyclic deformation after switching off the electric drive of the installation, the sample remained clamped and the active loading was replaced by the relaxation stage. Subsequently, the samples were cooled with air a water-air mixture and naturally to room temperature (Voronin et al., 2016). The grids for metallographic analysis were prepared according to the traditional method on grinding and polishing circles. To etch samples a solution of nitric acid in ethyl alcohol was used.

\section{MATERIALS AND METHODS}

The purpose of this section's thesis is to study the effect of the austenitization regime, hot deformation and subsequent water-air cooling with the speeds of the new outlying roller table on the structure and properties of carbon steel sheets (Fig. 1). The effect of cooling with a water-air mixture on the structure and properties of rolled sheets of steel 60C2XA having the following chemical composition \%: C 0.64, Si 1.6, Mn 0.6, Ni 0.23, S 0.21, P $0.025, \mathrm{Cu} 0.2, \mathrm{Cr} 0.8$.

To study the austenitization, samples were taken $25 \pm 2 \mathrm{~mm}$ in length and subjected to heating to temperatures of $800-1050^{\circ} \mathrm{C}$ in $50^{\circ} \mathrm{C}$ increments and a holding time of $1 \mathrm{~min} / \mathrm{mm}$ followed by gradient quenching (the procedure was normalized GOST 5639) (Fig. 2).

To determine the size of austenitic grain a special reagent consisting of $1-4 \mathrm{~g}$ of picric acid, $3-5 \mathrm{~mL}$ of hydrochloric acid, $95-100 \mathrm{~mL}$ of ethyl alcohol was used. The grain size of the austenite was counted by means of an eye piece with a ruler on the MIM-7 microscope with an increase of 100 . To determine the influence of the degree deformation and subsequent water-air cooling with



Fig. 1: Force impacts at sheet shape control

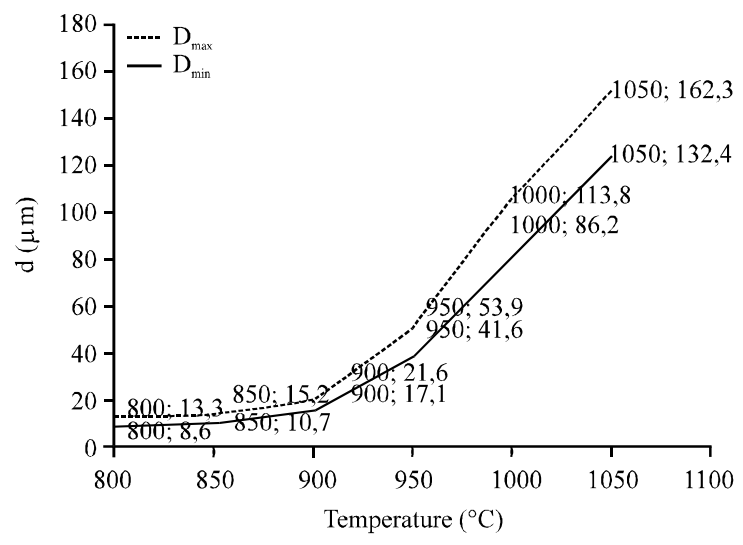

Fig. 2: Dependence of the grain size D $(\mathrm{mkm})$ on the austenitization temperature $\left({ }^{\circ} \mathrm{C}\right)$ at a specific exposure of $1 \mathrm{~min} / \mathrm{mm}$ cross section

the speeds of the new discharge roller table on the structure of $60 \mathrm{C} 2 \mathrm{XA}$ steel, samples with a size of $\varnothing 10.0 \times 15.0 \mathrm{~mm}$ were tested by compression on the Gleeble-3800 test complex. Plastic deformation of samples from steel 60C2XA was carried out on the module "Stretching-compression". The samples were heated at a rate of $100^{\circ} \mathrm{C} / \mathrm{sec}$ to 850 and $1050^{\circ} \mathrm{C}$ and held at these temperatures $1 \mathrm{~h}$. Further, each heated sample after 
(a)
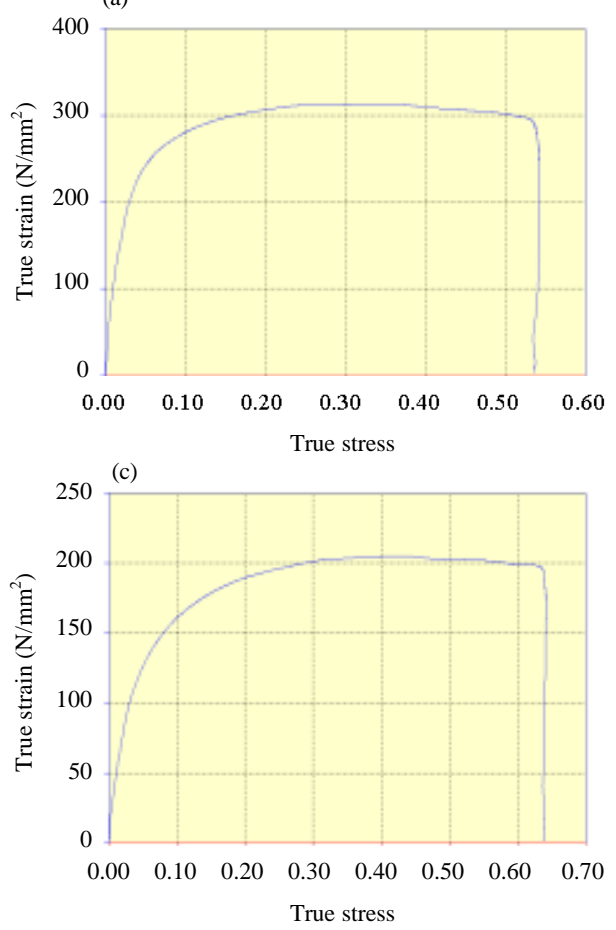

(b)
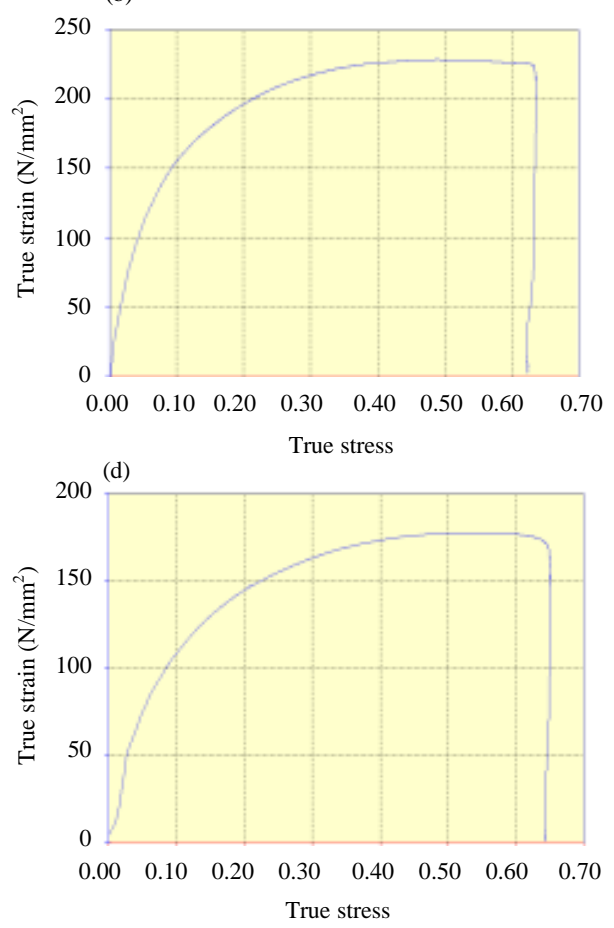

Fig. 3: The change in the deformation resistance of $60 \mathrm{C} 2 \mathrm{XA}$ steel at the temperature of the precipitation; a) $700^{\circ} \mathrm{C}$; b) $800^{\circ} \mathrm{C}$; c) $900^{\circ} \mathrm{C}$ and d) $1000^{\circ} \mathrm{C}$

cooling or heating to $700-1000^{\circ} \mathrm{C}$ was deformed by compression and cooled for 3 and $6 \mathrm{sec}$ by air blasting and by flowing with water. Subsequently, the resulting samples were cooled naturally to room temperature (Deshpande and Murthy, 1997). The grids for metallographic analysis were prepared according to the traditional method on grinding and polishing circles. To etch samples, a solution of nitric acid in ethyl alcohol was used. After the physical simulation of the cooling on a new-purpose discharge roller table, the quantitative analysis of the final microstructures was performed on the processed samples using a universal NEOPHOT 32 (Karl Zeiss, Jena) microscope (Germany). The micro hardness on a PMT-3 device with a load of $1 \mathrm{~N}$ was measured on the deformed and water-air mixture of cooled samples. The dependence of the grain size on the austenitization temperature is presented in Fig. 2. With an increase in the austenitization temperature, the average grain size of the austenite increases. Up to a temperature of $850^{\circ} \mathrm{C}$, the size of the austenite grains practically increases little and amounts to $12.95 \mathrm{mkm}$. Figure 3 shows the laws of the change in the resistance of deformation as a function of a single reduction. Analysis and comparison of the curves of the hardening of $60 \mathrm{C} 2 \mathrm{XA}$ steel shown in this figure show that the deformation resistance of 60C2XA steel at $700-1000^{\circ} \mathrm{C}$ for all the studied deformation rates increases at the initial moment of deformation and then deforms at constant stress (Zhong-feng et al., 2011). This is due to the fact that during the hot plastic deformation in the metal of the sample, two processes occur in parallel, hardening and softening which is due to the processes of dynamic polygonization and recrystallization. The relationship between them like the nature of the emerging structure depends on such parameters as temperature, degree and strain rate.

\section{RESULTS AND DISCUSSION}

In our opinion, the above-mentioned dynamic softening processes and the thermal deformation effect have a significant effect on the obtained deformation resistance curves (Karandaev et al., 2017). The results of the study showed that deformation at a temperature of $1000^{\circ} \mathrm{C}$ and cooling by a water-air mixture for 3 and $6 \mathrm{sec}$ promotes the formation of a completely recrystallized ferritic-sorbitol structure in a coarse-grained austenite structure Fig. $4 \mathrm{a}$ and b. Deformation at $900^{\circ} \mathrm{C}$ and cooling for 3 and $6 \mathrm{sec}$ leads to a decrease in the degree of recrystallization to 15 and $30 \%$, respectively, Fig. $4 \mathrm{c}$ and $\mathrm{d}$. At the same time a heterogeneous structure is formed in the preform which is associated with the appearance of large non-recrystallized grains in the shallow-grained 
(a)

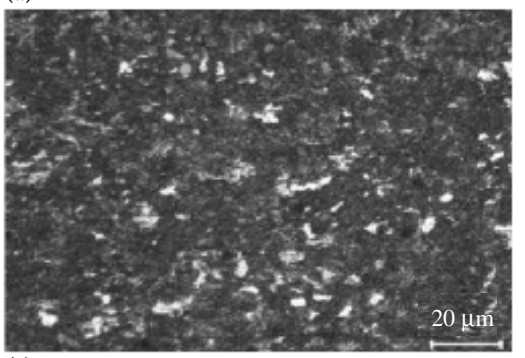

(c)

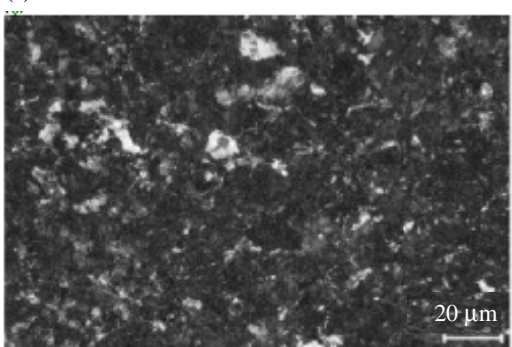

(b)

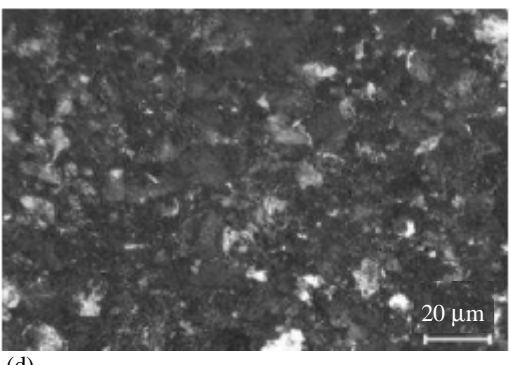

(d)

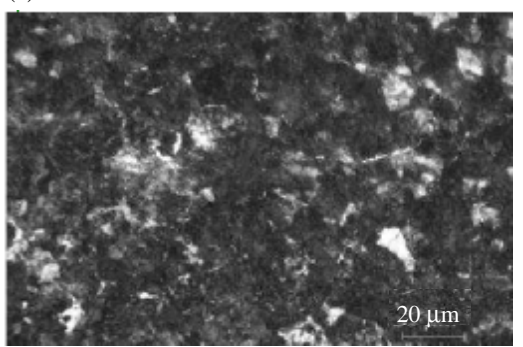

Fig. 4: The microstructure of steel $60 \mathrm{C} 2 \mathrm{XA}$ after austenitization at a temperature of $850^{\circ} \mathrm{C}$ with an exposure of $1 \mathrm{~h}$ and subsequent hot deformation at temperatures of 900 and $1000^{\circ} \mathrm{C}$ and cooling for 3 and $6 \mathrm{sec} ;$ a) Sediment at $900^{\circ} \mathrm{C}$ and cooling $3 \mathrm{sec}$; b) Sediment at $900^{\circ} \mathrm{C}$ and cooling $6 \mathrm{sec}$; c) Sediment at $1000^{\circ} \mathrm{C}$ and cooling $3 \mathrm{sec}$ and d) Sediment at $1000^{\circ} \mathrm{C}$ and cooling $6 \mathrm{sec}$

(a)

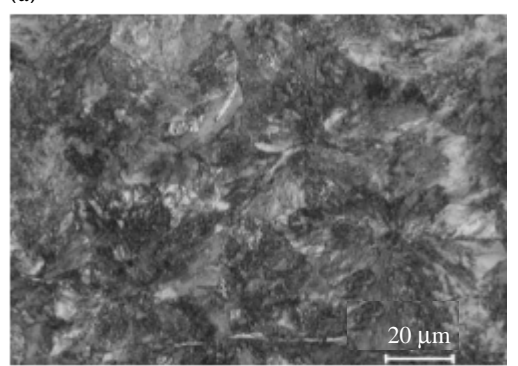

(c)

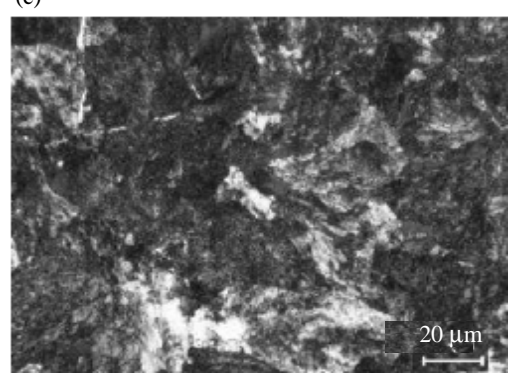

(b)

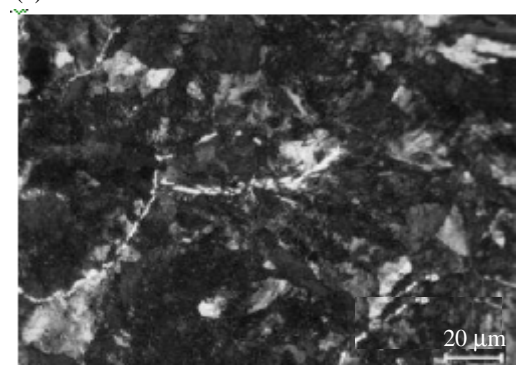

(d)

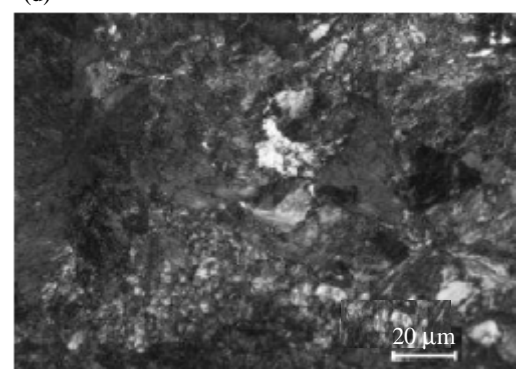

Fig. 5: The microstructure of $60 \mathrm{C} 2 \mathrm{XA}$ steel after austenitization at $850^{\circ} \mathrm{C}$ with a holding time of $1 \mathrm{~h}$ and subsequent hot deformation at temperatures of 700 and $800^{\circ} \mathrm{C}$ and cooling for 3 and $6 \mathrm{sec}$; a) Sediment at $700^{\circ} \mathrm{C}$ and cooling $3 \mathrm{sec}$; b) Sediment at $700^{\circ} \mathrm{C}$ and cooling $6 \mathrm{sec} ; \mathrm{c}$ ) Sediment at $800^{\circ} \mathrm{C}$ and cooling $3 \mathrm{sec}$ and d) Sediment at $800^{\circ} \mathrm{C}$ and cooling $6 \mathrm{sec}$

structure (Maklakova et al., 2015). In the case of precipitation at 700 and $800^{\circ} \mathrm{C}$ and cooling for 3 and $6 \mathrm{sec}$, the metal structure is not recrystallized
(Fig. 5). The structure of the metal consists of deformed elongated in the radial billet ferritic-sorbitol colonies. 

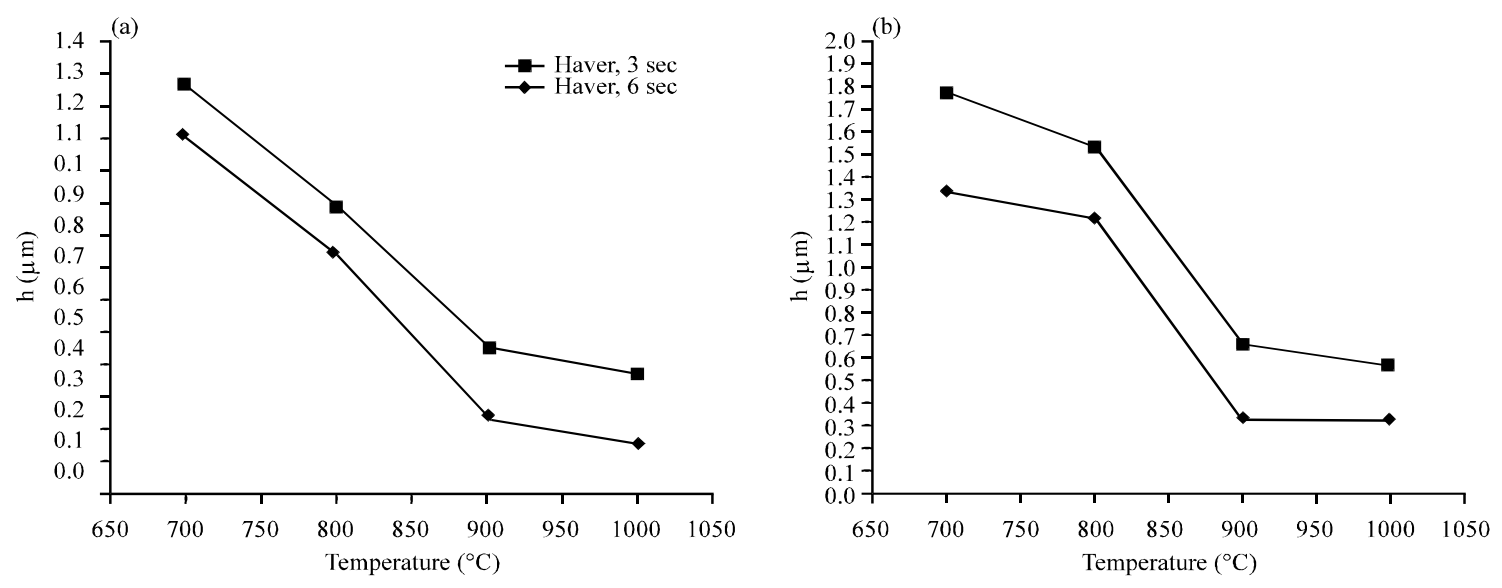

Fig. 6: Change in the inter plastic distance of the ferritic-sorbitol colony upon heating for austenitization; a) $850^{\circ} \mathrm{C}$ and b) $1050^{\circ} \mathrm{C}$ and a draft with a degree of $55-65 \%$ and a water-air-cooled mixture $\left(\mathrm{h}-\mathrm{T},{ }^{\circ} \mathrm{C}\right)$

It was established by the investigation that hot deformation at different temperatures with subsequent cooling leads to a change in the dispersion of perlite. An increase in the degree of deformation within the range of $60-65 \%$ leads to a decrease in the values of the interplastic distance as a result of the formation of a smaller austenite grain and a ferritic-sorbitol colony (Shilyaev et al., 2013). Thus, measuring the inter plastic distance shows that heating the samples to $700^{\circ} \mathrm{C}$, deforming with a degree of hot deformation of $55-65 \%$ and cooling for 3 and $6 \mathrm{sec}$ leads to the formation in a fine-grained austenite structure of thin-plate perlite with an interlattice distance of about $1.32-1.36$ and 1.12-1.23 $\mu$ m, respectively (Fig. 6). At the same time, deformation of samples with a degree of hot deformation of $55-65 \%$ at a temperature of $800^{\circ} \mathrm{C}$ and subsequent cooling of 3 and $6 \mathrm{sec}$ leads to the formation in a fine-grained austenite structure of thin-plate perlite with an interplanar distance of about 0.92-0.96 and $0.74-0.82 \mathrm{mkm}$, respectively (Fig. 6). Austenitization at a temperature of $850^{\circ} \mathrm{C}$, heating to a temperature of 900 and $1000^{\circ} \mathrm{C}$ followed by a deformation of $65 \%$ and cooling with a water-air mixture of $3 \mathrm{sec}$ leads to the production of high-carbon sorbitol steel in the structure with an interplanar distance of the order of 0.45-0.51 and 0.37-0.41 $\mathrm{mkm}$, respectively. As the holding time increases to $6 \mathrm{sec}$, the interplanar distance decreases to $0.22-0.28$ at $900^{\circ} \mathrm{C}$ and up to $0.14-0.18 \mathrm{mkm}$ at $1000^{\circ} \mathrm{C}$ (Fig. 6).

It can be noted that the small average grain size of the initial austenite ensures the formation of a fine-grained ferritic-sorbitol structure after the ferritic transformation process and leads to a decrease in the size of the sorbitol colonies formed as a result of the pearlite reaction
(Randak, 1985). With a content of 0.64 carbons, most of the ferrite is released not in the form of distant grains but in the grinding wheel around the grains are observed on the section as a ferrite mesh. Measurement of the interplate distance of the ferritic-sorbitol colony showed that heating for austenitization at $1050^{\circ} \mathrm{C}$ a subsequent precipitate with a degree of $55-65 \%$ at $700,800^{\circ} \mathrm{C}$ and water-air mixture cooling with a time of $3 \mathrm{sec}$ leads to the formation of a microstructure with an interplanar distance 1.83-1.89 and 1.56-1.64 mkm (Fig. 6b) that is structures of coarse-lamellar perlite (Voronin et al., 2016). As the holding time increases to $6 \mathrm{sec}$ the interplanar distance decreases to $1.36-1.44$ and $1.24-0.31 \mathrm{mkm}$, respectively (Fig. 6b) and the sizes and number of pearlite colonies increase. Austenitization at a temperature of $1050^{\circ} \mathrm{C}$, heating to a temperature of 900 and $1000^{\circ} \mathrm{C}$ followed by deformation with a degree of $55-65 \%$ and cooling with a water-air mixture of $3 \mathrm{sec}$ leads to the production of highcarbon sorbitol steel in the structure with an inter-plate distance of about $0.67-0.72$ and $0.57-0.62 \mathrm{mkm}$. As the holding time increases to $6 \mathrm{sec}$, the interplanar distance decreases to $0.57-0.61 \mathrm{mkm}$ at $900^{\circ} \mathrm{C}$ and up to $0.31-0.37$ $\mathrm{mkm}$ at $1000^{\circ} \mathrm{C}$ (Fig. 6b). A study of hardness showed that hot deformation at different temperatures with subsequent cooling by a water-air mixture leads to a change in the micro hardness of perlite (Randak, 1985). An increase in the degree of deformation within the range of $60-65 \%$ leads to an increase in the values of micro hardness as a result of pulling out colonies of ferritic-sorbitol colonies or forming smaller grains.

The average micro hardness of fine-grained samples precipitated at 700 and $800^{\circ} \mathrm{C}$ and cooled by water-air 
(a)

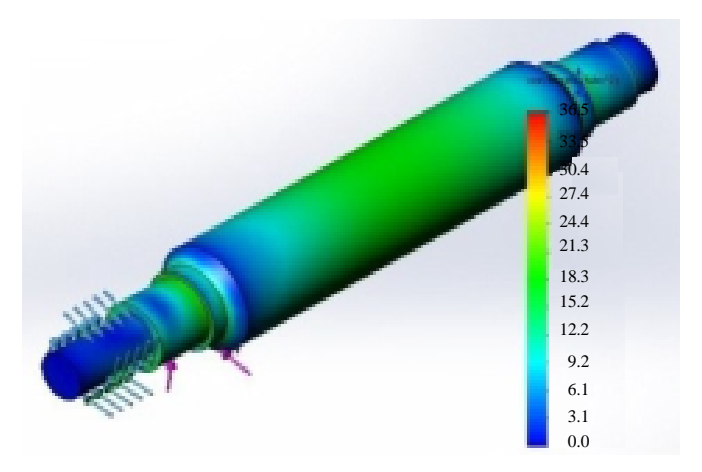

(b)

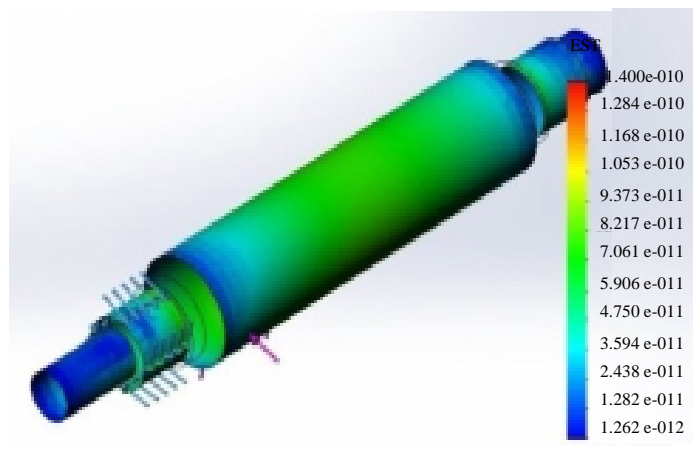

(c)

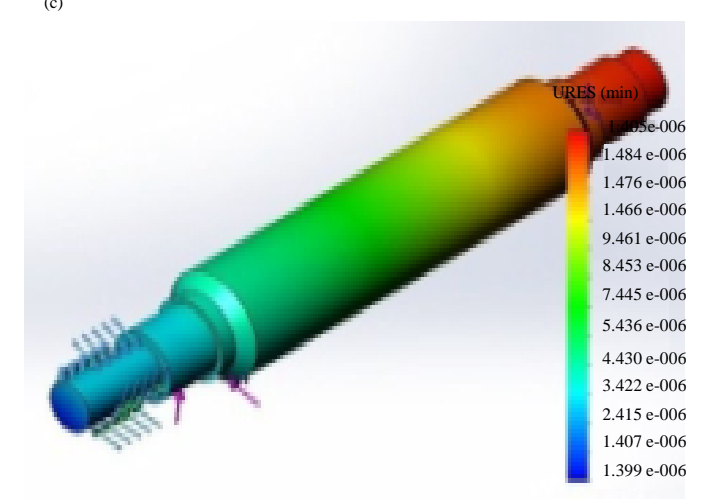

Fig. 7: The picture of the distribution of equivalent stresses; a) And deformations; b) As well as the total displacements and c) In the rollers during the transportation of the strips in a roller conveyor with lower air pressure

mixture $3 \mathrm{sec}$ is $3658 \mathrm{MPa}$ (3364 MPa at the center and $3823 \mathrm{MPa}$ at the surface) and $3593 \mathrm{MPa}$ (3294 MPa at the center and $3976 \mathrm{MPa}$ at the surface) and cooled $6 \mathrm{sec}$ is equal to $3805 \mathrm{MPa}$ (3618 MPa in the center and $3992 \mathrm{MPa}$ at the surface) and $3735 \mathrm{MPa}(3417 \mathrm{MPa}$ in the center and $3942 \mathrm{MPa}$ at the surface), respectively. The micro hardness of the samples deposited at 900 and $1000^{\circ} \mathrm{C}$ and cooled by the water-air mixture $3 \mathrm{sec}$ is equal to $3319 \mathrm{MPa}$ (3246 MPa at the center and $3393 \mathrm{MPa}$ at the surface) and $3078 \mathrm{MPa}$ (2932 MPa in the center and $3224 \mathrm{MPa}$ at the surface) and the cooled $6 \mathrm{sec}$ is respectively, $3416 \mathrm{MPa}$ (3141 MPa in the center and $3691 \mathrm{MPa}$ at the surface) and $3287 \mathrm{MPa}$ (2958 MPa in the center and $3617 \mathrm{MPa}$ at the surface) (Fig. 7).

The obtained values of micro hardness confirm the fact that as the precipitation temperature decreases and the time of water-air cooling increases, the micro hardness increases (Voronin et al., 2016). The obtained data also indicate that the hardness of the samples in the longitudinal and transverse directions is small there is not a wide range of properties when cooling with a water-air mixture.

\section{CONCLUSION}

To ensure the rational structure of rolled steel A1, it is necessary to roll strips with the end-of-rolling temperature of $900^{\circ} \mathrm{C}$ the cooling temperature is $600-650^{\circ} \mathrm{C}$ while the hot-rolled strips on the outgoing roller table must be cooled by the water-air mixture according to the early cooling regime. Heating to temperatures of $700-800^{\circ} \mathrm{C}$ and deformation with a degree of $65-70 \%$ when cooling with a water-air mixture of 3 and $6 \mathrm{sec}$ does not always ensure the formation of a fine-grained ferritic-sorbitol structure in high-carbon samples.

Heating to $1000^{\circ} \mathrm{C}$, deformation with a degree of $65-70 \%$ cooling with a water-air mixture for 3 and $6 \mathrm{sec}$ leads to the formation of a fine-grained ferritic-sorbitol structure in samples of diameters and chemical composition studied. As the cooling time decreases and the test temperature increases, the micro hardness of the samples decreases while the amount of structurally free ferrite increases. Heating of the samples to temperatures of 900 and $1000^{\circ} \mathrm{C}$, deformation with a degree of $65-70 \%$ and cooling by a water-air mixture 3 and $6 \mathrm{sec}$ leads to the 
formation of a sorbitol structure in samples of high-carbon steel with an interplastic distance of $0.23-0.62 \mathrm{mkm}$. As the cooling time increases, the interlaminar distance decreases and the size of the pearlite colonies increases.

\section{REFERENCES}

Deshpande, A.S. and K.S. Murthy, 1997. Computer analysis for the prediction of a strip profile in cold rolling. J. Mater. =Process. $=$ Technol., 63: 712-717.

Karandaev, A.S., B.M. Loginov, V.R. Gasiyarov and V.R. Khramshin, 2017. Force limiting at roll axial shifting of plate mill. Procedia Eng., 206: 1780-1786.

Maklakova, E.A., A.S. Maklakov, V.R. Gasiyarov and S.S. Voronin, 2015. The work roll bending control system of the hot plate rolling mill. Procedia Eng., 129: $37-41$.
Randak, A., 1985. New solutions for steel and rolled Iron manufacture. Ferrous Met., 12: 8-14.

Shilyaev, P. V., I. Y. Andryushin, V. V. Golovin, A. A. Radionov and A.S. Karandaev, 2013. Algorithms of a digital automatic system for tension and loop control in a wide-strip hot-rolling mill. Russ. Electr. Eng., 84: 533-541.

Voronin, S., D.Y. Usatyi, V.R. Gasiyarov and A.A. Radionov, 2016. Analysis of the use of cambered roll with the roll shift system CVC to adjust the gap on the hot plate mill. Russ. Internet J. Ind. Eng., 3: 45-49.

Zhong-feng, G., S. Xue-yan, W. Qi, Z. Yi and G. Hui, 2011. Simulation of shape control for CVC hot strip rolling. Procedia Eng., 15: 1166-1170. 